\title{
POETS WITH HISTORY/POETS WITHOUT HISTORY
}

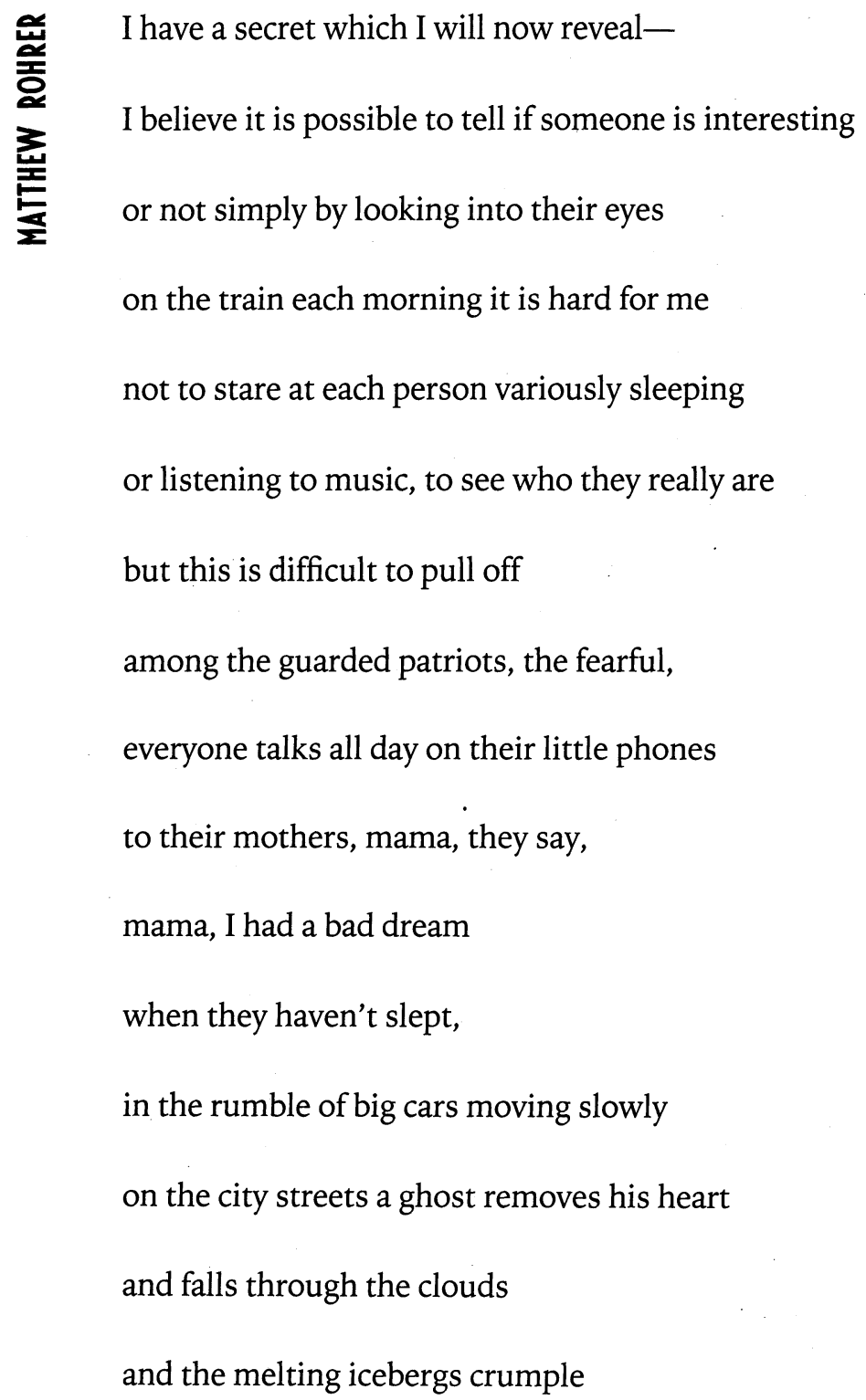


like a prisoner shot in the side

I move through the days remarkably sinuously

and spinning inside

I wash the dishes 2 or 3 times a day

with the hot water on and on

like a dream behind the yellow gloves

from which I too cannot awaken

136

though my son is done with school

and holds my hand on the walk home

the feeling of falling backwards

into the bed at night fills me

each time

with sweet content

all the people rounded up in camps

have a look in their eyes

that can't reach us now

\section{The Iowa Review}

